\title{
Fingerprinting aeolian dust in marine sediment: examples from Australia
}

Patrick De Deckker

\begin{abstract}
Methods to identify airborne material in deep-sea sediment cores and track dust provenance are reviewed here. An example from Australia demonstrates how evidence from $\mathrm{Sr}$ and $\mathrm{Nd}$ isotopes and rare earth elements can reveal the climatic history with sub-regional detail.
\end{abstract}

The quest to identify the aeolian component among the terrigenous material deposited at sea relies on a whole suite of techniques that can be applied to determine the presence of airborne dust in deep-sea sediment cores and to track its origin:

(1) The percentage of the quartz fraction in sediment cores from the deep ocean and the continental shelves gives an indication of the airborne fraction, based on the assumption that the quartz particles were wind blown. This approach was first applied by Thiede (1979) in the Tasman Sea, east of Australia.

(2) The size of quartz grains and their texture, i.e. the pitted depressions of desert sand grains from collisions during saltation, contain information on wind speed, the degree of storminess, and the distance traveled from land. Rea and colleagues used such an approach in sediment cores from the northwestern and central Pacific Ocean (Janecek 1985; Rea 1990, 1994).

(3) The proportion of different clay species can reflect the mode of sediment transport. Comparison of the clay composition in deep-sea sediment cores with clays from nearby rivers and dune fields can provide a quantitative measure for the relative importance of fluvial and aeolian transport. Such an approach was performed by Gingele et al. (2001) who differentiated riverine from airborne clays offshore northern Australia.

(4) Using the same approach and samples as Gingele et al. (2001), Ehlert et al. (2011) were able to consolidate the previous findings using a combination of $\mathrm{Pb}, \mathrm{Nd}$ and $\mathrm{Sr}$ isotopes. In this latter study, Ehlert et al. (2011) were able to identify the origin of fluvial clays and define patterns of oceanic currents at the sea surface during and after the Last Glacial Maximum.
(5) Rare earth elements (REE) in deep-sea core sediments. The REE composition and geochemistry is specific to each ablation area. This REE signature can help identify the origin of the material deposited at sea. (See example below on the use of Yttrium).

(6) Sr and Nd isotopes from regolith samples such as in Australia can help constrain the origin of the deep-sea sediments provided there is sufficient information on the composition of the regolith that can potentially supply material at sea, either airborne or by fluvial discharge.

(7) X-ray fluorescence scanning of soft marine sediments at a centimeter to sub-millimeter scale for a variety of elements (see Weltje and Tjallingii 2008) can be used to estimate the relative contributions of fluvial and aeolian material. Some elemental ratios such as $\mathrm{K} / \mathrm{Ca}$ and $\mathrm{Rb} / \mathrm{Ca}$ relate to continental weathering whereas others such as Ti/Ca,

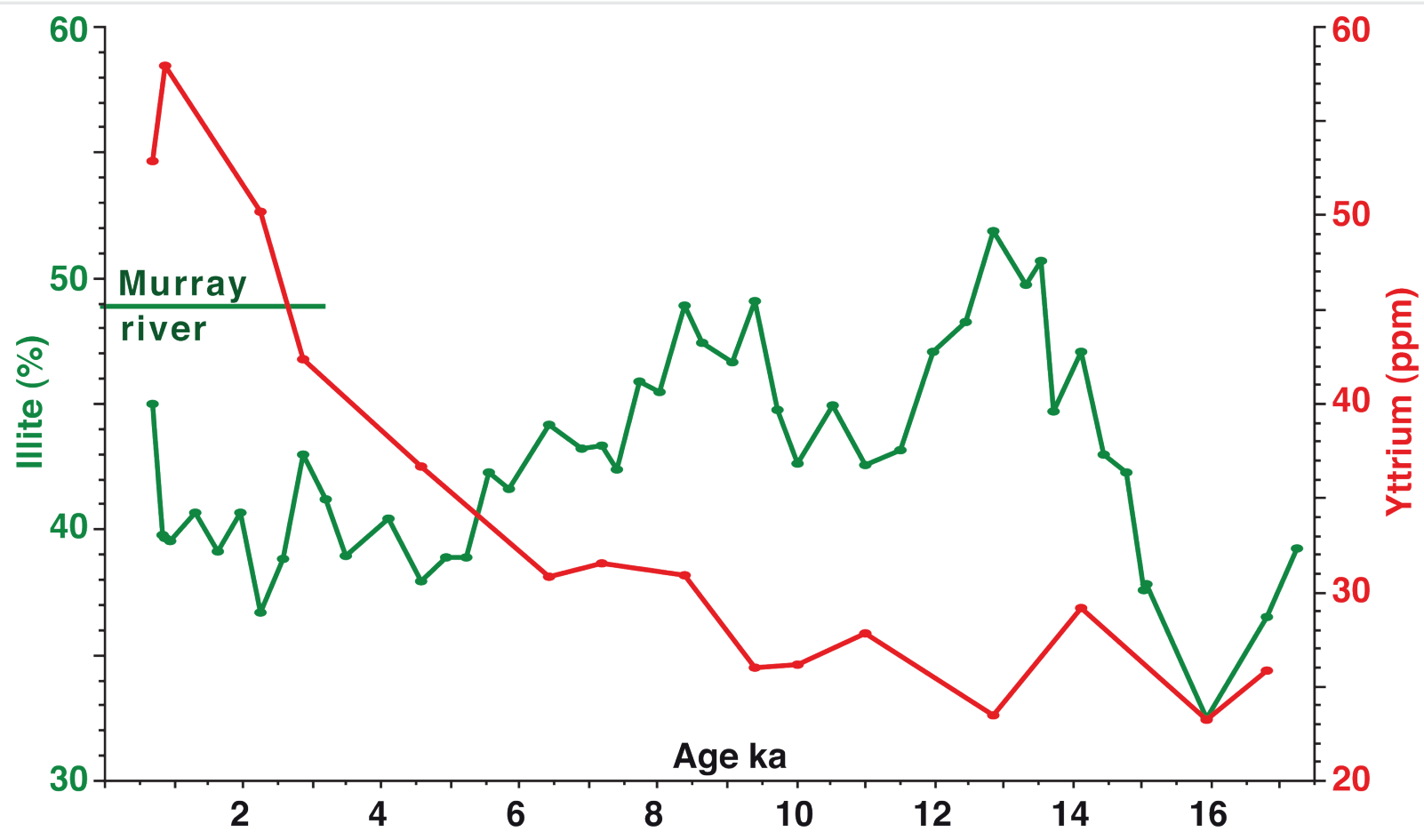

Figure 1: Illite and yttrium concentrations in sediment core MD03-2611 offshore Kangaroo Island for the last 17 ka. The horizontal line shows the illite percentage at the mouth of the Murray River today. The two illite peaks around 14-12 ka and 10-8 ka represent significant water discharge from the eastern highlands of SE Australia. The yttrium increase shows a change to predominantly aeolian sediment supply after 6 ka. 


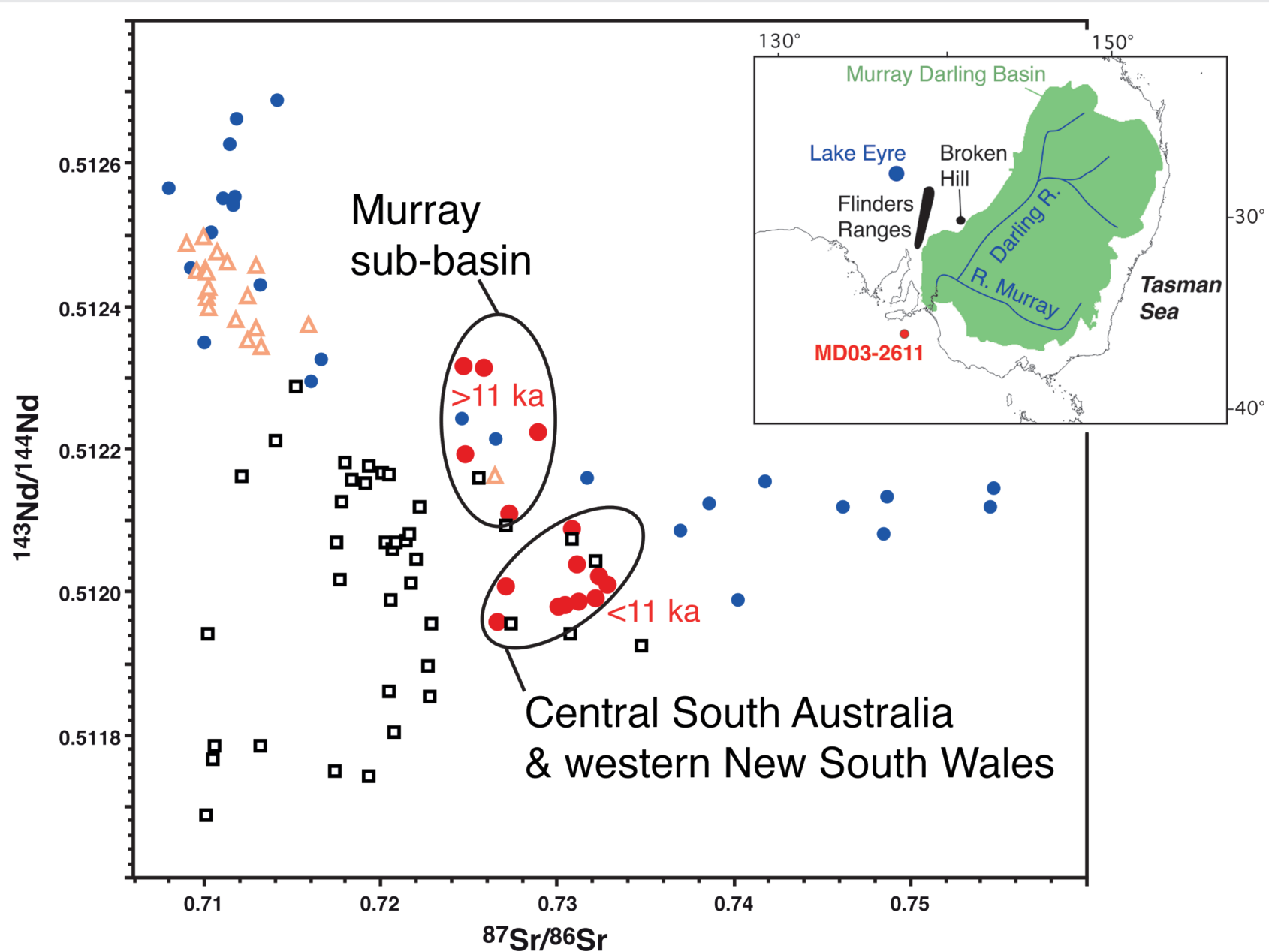

Figure 2: Plot of Sr and Nd isotopes for sediment core MD03-2611 (red dots) and from regolith samples in eastern and central Australia that are considered potential sources of airborne dust. Blue dots represent tributaries of the River Murray and Darling River. The Nd isotopic ratios above 0.51255 pertain to Darling River tributaries that share similarities with samples from the Lake Eyre region (orange triangles). Black squares represent samples from west and east of the Flinders Ranges and from western New South Wales near Broken Hill. The samples aged $>11$ ka BP come from the Murray sub-basin and would have been transported to the core site by water (thus being river borne), whereas the younger samples come from central South Australia and western New South Wales, and are considered to have been airborne, being from outside the Murray Darling Basin.

$\mathrm{Si} / \mathrm{Ca}$ and $\mathrm{Zr} / \mathrm{Ca}$ relate to an aeolian component. This was recently demonstrated for a core taken offshore northwestern Western Australia by Stuut et al. (2014).

\section{Application to marine \\ sediments off Australia}

Deep-sea sediment core MD03-2611 was taken offshore South Australia, opposite the mouth of the Murray River that together with the Darling River system drains the extensive $\left(1.10^{6} \mathrm{~km}^{2}\right.$ ) Murray Darling Basin (map in Fig. 1). De Deckker et al. (in press) analyzed selected samples from that core with several of the methods listed above to constrain the chemical signature of various parts of the Australian regolith.

The relative abundance of the clay species illite, smectite, and kaolinite, combined with $\mathrm{Sr}$ and $\mathrm{Nd}$ isotope ratios of the clay fraction (Gingele et al. (2007) revealed the flooding history of the Murray Darling Basin. Clay speciation (Fig. 1) varied substantially over the last $17 \mathrm{ka}$. The surprise was to find a drop in illite content during the Holocene, which indicates prevalence of an aeolian component from a remote source during the last $6 \mathrm{ka}$, since what was recognized as the clay sediments did not pertain to the Murray Darling Basin. This period of aeolian activity is also recognized in the $\mathrm{Sr}$ and $\mathrm{Nd}$ isotope records
(Fig. 2). The history of increasing supply of airborne sediment paralleled a progressive sea-surface cooling determined by alkenone chemistry carried out on the same sediment core (Calvo et al. 2007).

The increase in the concentration of the REE yttrium following $6 \mathrm{ka} \mathrm{BP}$ also points to a fundamental change in the supply source of terrigenous material to the core site (Fig. 1). Furthermore, $\mathrm{Sr}$ and $\mathrm{Nd}$ isotopes compared to the Australian regolith constrain the origin of the sediments in core MD03-2611. Figure 2 shows the spread of $\mathrm{Sr}$ and $\mathrm{Nd}$ isotopes for different regions in the southeastern sector of Australia, all of which are considered potential dust sources (De Deckker et al., in press). Sr and Nd ratios in core MD03-2611 suggest that prior to $10 \mathrm{ka} B P$ the sediment originated from the Murray sub-basin, after that from regions outside the Murray Darling Basin. Likely distal sources are central South Australia and western New South Wales, implying an aeolian transport mechanism to the sediment core site.

\section{Conclusion}

An array of traditional and new approaches for studying sediments in marine sediment cores can fingerprint the origin and indicate the transport mechanism of the terrigenous material deposited at sea. Methods include clay speciation and the chemical composition of the clay fraction such as $\mathrm{Sr}$ and $\mathrm{Nd}$ isotopes and REE. Core scanning that allows us to determine various elements at high resolution (but not in a quantitative way) also provides a new tool for distinguishing aeolian from fluvial components. The scanning method is non-destructive, relatively inexpensive and rapid and, therefore, can inform us which analytical techniques are best applied to identify the airborne fraction of marine and other sediments.

\section{AFFILIATIONS}

Research School of Earth Sciences, The Australian National University, Canberra, Australia

\section{CONTACT}

Patrick De Deckker: patrick.dedeckker@anu.edu.au

\section{REFERENCES}

\section{Full reference list under:}

www.pages-igbp.org/products/magazine/ref2014_2.pdf De Deckker P et al. (in press) Aeolian Research, doi:10.1016/j.aeolia.2014.07.003

Ehlert C et al. (2011) Geochem Geophys Geosyst 12, doi:10.1029/2011GC003544

Gingele FX et al. (2007) Earth Planet Sci Lett 255: 257-272 Stuut JB et al. (2014) Quat Sci Rev 83: 83-94

Weltje GJ, Tjallingii R (2008) Earth Planet Sci Lett 274: 423-438 